\title{
DEFISIENSI SISI-AJAIB SUPER DARI GRAF RANTAI
}

\author{
RARA RIZHKI GRACELIA \\ Program Studi Matematika, \\ Fakultas Matematika dan Ilmu Pengetahuan Alam, Universitas Andalas, \\ Kampus UNAND Limau Manis Padang, Indonesia, \\ rararizhki@gmail.com
}

\begin{abstract}
Abstrak. Misal terdapat graf $G=(V, E)$ dengan $|V|=p$ dan $|E|=q$. Suatu graf $G$ merupakan graf total sisi-ajaib jika terdapat pemetaan bijektif $f$ dari $V(G) \cup E(G)$ ke $\{1,2,3, \cdots, p+q\}$, dengan sifat bahwa untuk setiap sisi pada graf tersebut jumlah label sisi dan label kedua titik ujungnya sama. Berkaitan dengan hal tersebut diperkenalkan konsep defisiensi sisi-ajaib (super) dari suatu graf. Konsep ini menyatakan seberapa dekat suatu graf dengan suatu graf yang mempunyai pelabelan total sisi-ajaib (super). Pada tulisan ini akan dikaji kembali tentang defisiensi sisi-ajaib super dari graf rantai.
\end{abstract}

Kata Kunci: Graf rantai, pelabelan ajaib, defisiensi sisi-ajaib super

\section{Pendahuluan}

Dalam teori graf, pelabelan menjadi topik yang banyak mendapat perhatian, karena model-model yang ada pada pelabelan graf berguna untuk aplikasi yang luas, seperti dalam masalah peta jaringan jalan raya, jaringan internet, sistem alamat jaringan komunikasi, dan desain sirkuit. Pelabelan merupakan pemetaan bijektif yang memetakan elemen-elemen (titik atau sisi) dengan bilangan bulat positif yang disebut label. Pada suatu graf $G$ pelabelan total sisi-ajaib super adalah pelabelan total sisi-ajaib dimana label-label terkecil menjadi label titik.

Berkaitan dengan pelabelan total sisi-ajaib, diperkenalkan defisiensi sisi-ajaib yang menyatakan seberapa "dekat" suatu graf ke graf lain yang mempunyai pelabelan total sisi-ajaib. Untuk menentukan defisiensi sisi-ajaib super dari suatu graf rantai, diperlukan metode-metode tertentu dalam melabelkan suatu titik sedemikian sehingga didapatkan suatu konstanta ajaib yang nantinya akan digunakan untuk melabeli sisinya. Pada defisiensi sisi-ajaib super dari graf rantai $k K_{n^{-}}$ lintasan ada suatu bilangan bulat tak negatif terkecil $n$ sedemikian sehingga $k K_{n}$ lintasan $\cup n K_{1}$ merupakan suatu graf total sisi ajaib. Metode pelabelan titik dan sisi (pelabelan total) berbeda-beda dalam suatu graf, bergantung pada banyaknya titik dan sisi pada graf tersebut.

Lema 1.1. [1] Graf $G$ adalah ajaib super jika dan hanya jika terdapat fungsi bijektif $f(V)=\{1,2,3, \cdots, p\}$ sehingga himpunan $S=\{f(u)+f(v) \mid u v \in E(G)\}$ memuat $q$ bilangan bulat berurutan. Dalam hal ini $f$ dapat diperluas menjadi suatu pelabelan ajaib super dari $G$ dengan konstanta ajaib $C=p+q+\min (S)$. 


\section{Defisiensi Sisi-Ajaib Super dari Graf Rantai}

Graf rantai didefinisikan sebagai $k K_{n}$-lintasan, yaitu graf yang dapat dilihat sebagai graf lintasan, di mana setiap titik pada lintasan berupa graf lengkap $K_{n}$. Defisiensi sisi-ajaib super dari graf rantai diberikan dalam teorema berikut.

Teorema 2.1. [3] Jika $G$ adalah graf $k K_{n}$-lintasan dengan $k \equiv 3(\bmod 4)$, maka $\mu_{s} \leq k-1$.

Bukti. Misalkan $H \cong G \cup(k-1) K_{1}$ adalah graf yang mempunyai himpunan titik dan himpunan sisi sebagai berikut.

$$
\begin{aligned}
& V(H)=\left\{u_{i} \mid 1 \leq i \leq k+1\right\} \bigcup\left\{v_{i} \mid 1 \leq i \leq k\right\} \bigcup\left\{w_{i} \mid 1 \leq i \leq k-1\right\}, \\
& E(H)=\left\{u_{i} u_{i+1} \mid 1 \leq i \leq k\right\} \bigcup\left\{u_{i} v_{i}, u_{i+1} v_{i} \mid 1 \leq i \leq k\right\},
\end{aligned}
$$

untuk $k \equiv 3(\bmod 4)$. Dapat dilihat bahwa $|V(H)|=(k+1)+k+(k-1)=3 k$ dan $|E(H)|=3 k$. Pelabelan titik $f: V(H) \rightarrow\{1,2,3, \cdots, 3 k\}$, dapat dikonstruksikan sebagai berikut.

$$
f(x)= \begin{cases}\frac{1}{2}(1+i) & , \text { jika } x=u_{i} \text { untuk } i \text { ganjil, } 1 \leq i \leq k+1 \\ \frac{1}{2}(k+1+i) & , \text { jika } x=u_{i} \text { untuk } i \text { genap, } 2 \leq i \leq k+1 \\ 2 k+2-i & , \text { jika } x=v_{i} \text { untuk } i \text { ganjil, } 1 \leq i \leq k \\ 3 k+2-i & , \text { jika } x=v_{i} \text { untuk } i \text { genap, } 2 \leq i \leq k\end{cases}
$$

$f\left(\left\{w_{i} \mid 1 \leq i \leq k-1\right\}\right)=\{k+3, k+5, \cdots, 3 k-3,3 k-1\}$

Maka jumlah label titik dapat dinyatakan sebagai berikut

$$
\begin{aligned}
f\left(u_{i}\right)+f\left(u_{i+1}\right) & =\frac{1}{2}(k+3+2 i), 1 \leq i \leq k, \\
f\left(u_{i}\right)+f\left(v_{i}\right) & = \begin{cases}\frac{1}{2}(7 k+5-i), & \text { jika } i \text { genap, } \\
\frac{1}{2}(4 k+5-i), & \text { jika } i \text { ganjil. }\end{cases} \\
f\left(u_{i+1}\right)+f\left(v_{i}\right) & = \begin{cases}\frac{1}{2}(6 k+6-i), & \text { jika } i \text { genap } \\
\frac{1}{2}(5 k+6-i), & \text { jika } i \text { ganjil. }\end{cases}
\end{aligned}
$$

Sehingga

$$
\begin{aligned}
\left\{f\left(u_{i}\right)+f\left(u_{i+1}\right) \mid 1 \leq i \leq k\right\} & =\left\{\frac{1}{2}(k+5), \frac{1}{2}(k+7), \cdots, \frac{1}{2}(3 k+3)\right\}, \\
\left\{f\left(u_{i}\right)+f\left(v_{i}\right) \mid 1 \leq i \leq k\right\} & =\left\{\frac{1}{2}(3 k+5), \frac{1}{2}(3 k+7), \cdots, 2 k+2,3 k+3, \cdots, \frac{1}{2}(7 k+3)\right\}, \\
\left\{f\left(u_{i+1}\right)+f\left(v_{i}\right) \mid 1 \leq i \leq k\right\} & =\{2 k+3,2 k+4, \cdots, 3 k+2\} .
\end{aligned}
$$

Diperoleh bahwa $S=\{f(x)+f(y) \mid x y \in E(H)\}$ adalah himpunan bilangan bulat berurutan dengan $\min (S)=\frac{1}{2}(k+5)$. Berdasarkan Lema 1.1 diperoleh konstanta ajaib $\frac{1}{2}(13 k+5)$. Karena $f$ dapat diperluas menjadi suatu pelabelan ajaib sisi-ajaib super pada $H$, maka $\mu_{s}\left(k K_{3}\right.$-lintasan $) \leq k-1$.

Diberikan contoh untuk mengilustrasikan Teorema 2.1 pada graf rantai untuk $7 K_{3}$-lintasan $\bigcup 6 K_{1}$. Karena $7 \equiv 3(\bmod 4)$, maka dapat digunakan Teorema 2.1 

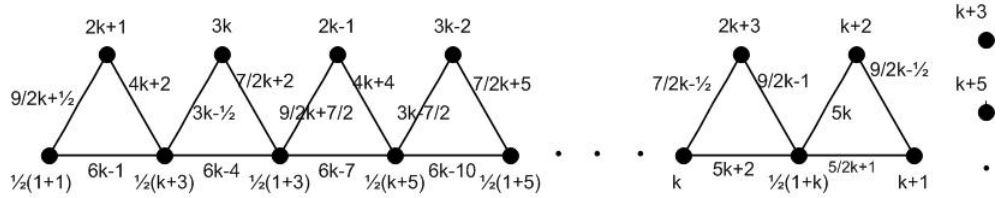

Gambar 2.1. Pelabelan titik dan sisi $H \cong G \bigcup(k-1) K_{1}$

untuk melabeli graf $H \cong 7 K_{3}$-lintasan $\cup 6 K_{1}$, sebagai berikut

$$
f(x)= \begin{cases}\frac{1}{2}(1+i), & \text { jika } x=u_{i} \text { untuk } i \text { ganjil, } 1 \leq i \leq 7, \\ \frac{1}{2}(k+1+i), & \text { jika } x=u_{i} \text { untuk } i \text { genap, } 2 \leq i \leq 8, \\ 2 k+2-i, & \text { jika } x=v_{i} \text { untuk } i \text { ganjil, } 1 \leq i \leq 7 \\ 3 k+2-i, & \text { jika } x=v_{i} \text { untuk } i \text { genap, } 2 \leq i \leq 8\end{cases}
$$

Diperoleh himpunan jumlah label titik sebagai berikut.

$$
\begin{aligned}
& \left\{f\left(u_{i}\right)+f\left(v_{i}\right) \mid 1 \leq i \leq 7, i \text { ganjil }\right\}=\{16,15,14,13\} \\
& \left\{f\left(u_{i}\right)+f\left(v_{i}\right) \mid 2 \leq i \leq 6, i \text { genap }\right\}=\{26,25,24\} \\
& \left\{f\left(u_{i}\right)+f\left(u_{i+1}\right) \mid 1 \leq i \leq 7, i \text { ganjil }\right\}=\{6,8,10,12\} \\
& \left\{f\left(u_{i}\right)+f\left(u_{i+1}\right) \mid 2 \leq i \leq 6, i \text { genap }\right\}=\{7,9,11\} \\
& \left\{f\left(u_{i}\right)+f\left(u_{i+1}\right) \mid 1 \leq i \leq 7, i \text { ganjil }\right\}=\{20,19,18,17\} \\
& \left\{f\left(u_{i}\right)+f\left(u_{i+1}\right) \mid 2 \leq i \leq 6, i \text { genap }\right\}=\{23,22,21\}
\end{aligned}
$$

Setelah diperoleh himpunan jumlah label titik dan $\min (S)=6$ sehingga berdasarkan Lema 1.1, diperoleh konstanta ajaib $C=p+q+\min (S)=48$. Dapat
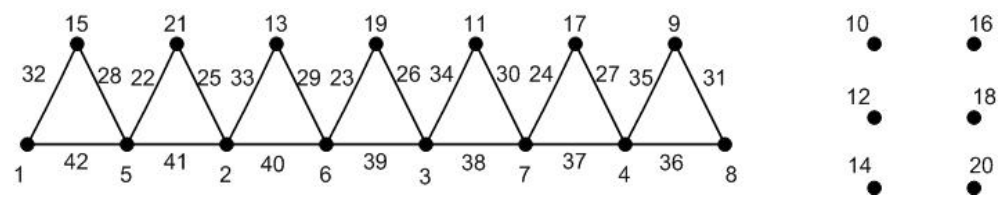

Gambar 2.2. Pelabelan titik dan sisi $G \bigcup 6 K_{1}$

dilihat bahwa karena pelabelan terhadap $G \cup 6 K_{1}$ adalah pelabelan super, sehingga defisiensi sisi-ajaib tersebut adalah defisiensi sisi-ajaib super.

\section{Defisiensi Sisi-Ajaib Super dari Graf Rantai}

Pada Teorema 3.1 berikut diberikan nilai defisiensi sisi-ajaib super dari graf rantai $k K_{4}$-lintasan. 
Teorema 3.1. [3] Untuk setiap bilangan bulat positif $k \geq 2$, defisiensi sisi-ajaib super dari graf rantai $k K_{4}$-lintasan adalah $\mu_{s}\left(k K_{4}\right.$-lintasan $)=1$.

Bukti. Misalkan himpunan titik dan himpunan sisi $k K_{4}$-lintasan didefinisikan sebagai berikut

$$
\begin{aligned}
& V(G)=\left\{u_{i} \mid 1 \leq i \leq k+1\right\} \bigcup\left\{v_{i}, w_{i} \mid 1 \leq i \leq k\right\}, \\
& E(G)=\left\{u_{i} u_{i+1}, u_{i} v_{i}, u_{i} w_{i}, v_{i} w_{i}, v_{i} u_{i+1}, w_{i} u_{i+1} \mid 1 \leq i \leq k\right\} .
\end{aligned}
$$

Pelabelan titik terhadap $H \cong G \cup K_{1}$, dengan $|V(G)|=3 k+1+1=3 k+2$ dan $|E(G)|=6 k$ dapat dikonstruksikan sebagai berikut.

$$
f(x)= \begin{cases}3 i-2, & \text { jika } x=u_{i} \text { untuk } 1 \leq i \leq k+1, \\ 3 i, & \text { jika } x=v_{i} \text { untuk } 1 \leq i \leq k, \\ 3 i+2, & \text { jika } x=w_{i} \text { untuk } 1 \leq i \leq k . \\ 2, & \text { jika } x=v\left(K_{1}\right) .\end{cases}
$$

Diperoleh himpunan jumlah label titik-titik tersebut.

$$
S=\{6 i-2,6 i-1,6 i, 6 i+1,6 i+2,6 i+3 \mid 1 \leq i \leq k\} .
$$

Tampak bahwa $S=\{f(x)+f(y) \mid x y \in E(H)\}$ adalah himpunan bilangan bulat berurutan dengan $\min (S)=4$. Berdasarkan Lema 1.1 diperoleh konstanta ajaib $(9 k+6)$. Fungsi $f$ dapat diperluas menjadi suatu pelabelan ajaib sisi-ajaib super pada $H$, maka $\mu_{s}\left(k K_{4}\right.$-lintasan $)=1$.

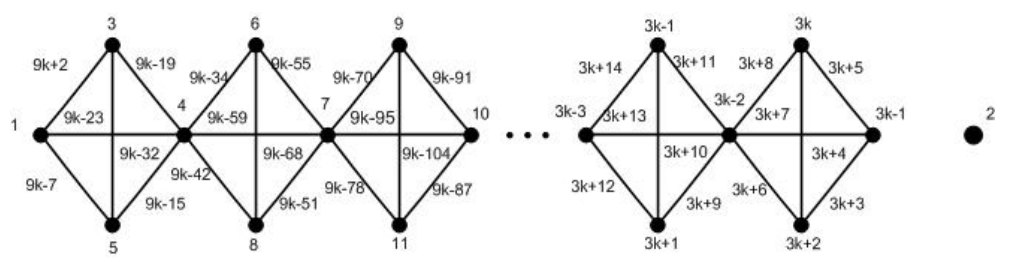

Gambar 3.1. Pelabelan titik dan sisi $H \cong k K_{4}$-lintasan $\bigcup K_{1}$

Berikut diberikan contoh untuk mengilustrasikan Teorema 2.1 pada graf rantai untuk $3 K_{4}$-lintasan $\bigcup K_{1}$.

$$
f(x)= \begin{cases}3 i-2, & \text { jika } x=u_{i} \text { untuk } 1 \leq i \leq 4, \\ 3 i, & \text { jika } x=v_{i} \text { untuk } 1 \leq i \leq 3 \\ 3 i+2, & \text { jika } x=w_{i} \text { untuk } 1 \leq i \leq 3, \\ 2, & \text { jika } x=v\left(K_{1}\right)\end{cases}
$$

Sehingga himpunan jumlah label titik dapat dinyatakan sebagai berikut:

$$
S=\{4,5,6,7,8,9,10,11,12,13,14,15,16,17,18,19,20,21\} .
$$

Karena $\min (S)=4$ maka berdasarkan Lema 1.1, diperoleh konstanta ajaib $C=$ $p+q+\min (S)=33$.

Dapat dilihat bahwa karena pelabelan terhadap $3 K_{4}$-lintasan $\cup 6 K_{1}$ adalah pelabelan super, sehingga defisiensi sisi-ajaib tersebut adalah defisiensi sisi-ajaib super. 


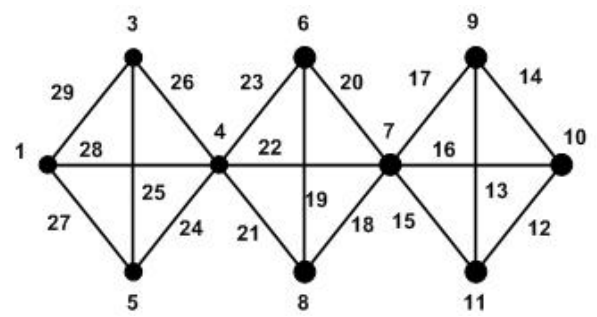

Gambar 3.2. Pelabelan titik dan sisi pada graf $3 K_{4}$-lintasan $\bigcup K_{1}$

\section{Kesimpulan}

Defisiensi sisi-ajaib super pada suatu graf rantai $\left(k K_{n}\right.$-lintasan) dapat ditentukan dengan menggabungkan suatu graf $G\left(k K_{n}\right.$-lintasan) dengan bilangan bulat tak negatif $n$ yang menghasilkan suatu graf total sisi-ajaib super atau tak berhingga jika bilangan bulat $n$ tersebut tidak ada. Untuk defisiensi sisi-ajaib dan defisiensi sisiajaib super pada graf rantai $k K_{n}$-lintasan untuk $n=3$ dan $k \equiv 3(\bmod 4)$ diperoleh bahwa defisiensi sisi-ajaib super untuk $k K_{3}$-lintasan, $\mu_{s}\left(k K_{3}\right.$-lintasan $) \leq k-1$, sementara untuk $n=4$, dan $k \geq 2$ diperoleh bahwa berlaku $\mu_{s}\left(k K_{4}\right.$-lintasan $)=1$.

\section{Ucapan Terima kasih}

Penulis mengucapkan terima kasih kepada Bapak Narwen, M.Si, Bapak Yudiantri Asdi, M.Sc, dan Ibu Izzati Rahmi HG, M.Si yang telah memberikan masukan dan saran sehingga makalah ini dapat diselesaikan dengan baik.

\section{Daftar Pustaka}

[1] Ngurah, A.A.G. 2007. Ketotalan Sisi-Ajaib Graf dan Defisiensinya. Disertasi S3, tidak diterbitkan.

[2] R.M. Figeuroa-Centano, R. Ichishima and F.A. Muntaner-Batle, The place of super edge-magic labelling among other classes of labelings. Discrete Math. 231 (2001) : $153-168$.

[3] R.M. Figeuroa-Centano, R. Ichishima and F.A. Muntaner-Batle, On the super edge-magic deficiency of graphs, Electron. Notes Discrete Math 11 (2002) : 299 -314 .

[4] R.M. Figeuroa-Centano, R. Ichishima and F.A. Muntaner-Batle, Some new results on the super edge-magic deficiency of graphs, J. Combin Math Combin Comput. 55 (2005) : $17-31$.

[5] R.M. Figeuroa-Centano, R. Ichishima and F.A. Muntaner-Batle, On super edgemagic graphs, Ars Combin. 64 (2002) : 81 - 95.

[6] S.M. Lee and J. Wang, On super edge-magicness of chain graphs whose blocks are complete graphs, Cong.Numer. 162 (2003) : $147-160$. 